\title{
Spontaneous remission of motor neuron disease, proposed relation to clove oil: A Case report
}

\section{Sawsan AlBaazi ${ }^{1 *}$, Hayder K. Hassoun ${ }^{2}$}

${ }^{1}$ Clinical Neurophysiologist, middle euphrates center of neurosciences, atheer alsakooni center of neurosciences, Najaf-Iraq.

${ }^{2}$ Consultant Neurologist, Kufa school of medicine, middle euphrates center of neursciences, atheer alsakooni center of neurosciences.

* Corresponding Author: Sawsan AlBaazi, Clinical Neurophysiologist, middle euphrates center of neurosciences, atheer alsakooni center of neurosciences, Najaf-Iraq.

Received date: 03 February 2022; Accepted date: 15 February 2022; Published date: 21 February 2022

Citation: AlBaazi S, Hassoun HK (2022) Spontaneous remission of motor neuron disease, proposed relation to clove oil: A Case report. J Med

Case Rep Case Series 3(02): https://doi.org/10.38207/JMCRCS/2022/FEB03020211

Copyright: ( 2022 Sawsan AlBaazi. This is an open-access article distributed under the terms of the Creative Commons Attribution License, which permits unrestricted use, distribution, and reproduction in any medium, provided the original author and source are credited.

\section{Introduction}

\section{Background}

Motor Neuron Disease (MND) is a neurodegenerative disorder characterized by selective motor neuron death. Patients develop a progressive muscle phenotype characterized by spasticity, hyperreflexia, fasciculations, muscle atrophy, and paralysis. Depending on the disease variant, upper or lower motor neurons are damaged, or both [1].

It is mostly associated with an irreversible progression of motor symptoms to death in a few years. Several case reports of secondary MND have been published, in which motor symptoms remitted after treatment of the underlying causes, such as lymphoma [2], carcinoma [3], cervical trauma [4], paraproteinaemia [5], and heavy metal intoxication [6].

Metals considered essential to humans are chromium, cobalt (Co), copper $(\mathrm{Cu})$, iron $(\mathrm{Fe})$, molybdenum, selenium $(\mathrm{Se})$, zinc $(\mathrm{Zn})$, and manganese $(\mathrm{Mn})$. In contrast to this essentiality some metals, for example, mercury $(\mathrm{Hg})$, but also cadmium $(\mathrm{Cd})$, arsenic (As), and lead $(\mathrm{Pb})$ lack biological functions and any exposure exceeding a low background may give rise to toxicity. Both essential and nonessential metals produce toxic effects when present in excess and these effects vary considerably depending on dose, duration, exposure conditions, bioavailability, and chemical species. [7,8,9]

\section{Case presentation}

A 60-year-old gentleman presented to AlSakooni neuroscience center- Najaf/Iraq in January 2021. The patient had diabetes mellitus and was advised by his friends to have herbals to control his blood sugar. he was advised to make a drink of concentrated clove oil. After having clove oil for three-time, the patient developed abdominal pain and diarrhea for a few days starting from the day of 3rd drink. 2 weeks later, he started to develop diffused muscle twitching, upper and lower limbs weakness, and then dysarthria and dysphagia.

$\mathrm{He}$ is a non-vegetarian. He worked in a grocery shop and there was no history of exposure to repeated electric shock. There was no
The antimicrobial activity of clove essentials oil has been studied against a large number of multi-resistant Staphylococcus epidermidis as well as the composition of the oil by GC/MS analysis [10]. Cytotoxicity of clove oil and its major components has been investigated by Prashar et al. The essential oil extracted from clove (Syzygium aromaticum) is used as a topical application to relieve pain and promote healing in herbal medicine and also finds use in the fragrance and flavouring industries.

Clove oil has two major components, eugenol, and $\beta$-caryophyllene, which constitute $78 \%$ and $13 \%$ of the oil, respectively. Clove oil and these components are generally recognized as 'safe', but the in-vitro study demonstrates cytotoxic properties of both the oil and eugenol, towards human fibroblasts and endothelial cells. Clove oil was found to be highly cytotoxic at concentrations as low as $0.03 \%$ with up to $73 \%$ of this effect attributable to eugenol. $\beta$-caryophyllene did not exhibit any cytotoxic activity, indicating that other cytotoxic components may also exist within the parent oil [11].

Spontaneous remission of non-symptomatic MND is extremely rare. Here, we report a case presented with progressive muscular atrophy disease (PMA) like the picture, who resolved spontaneously.

history of unprotected sexual intercourse. There was no suggestive family history. There was no history of alcohol excess or illicit drug usage.

On examination, he is of average build and nutrition. Other parts of the general examination were normal. Neurological examination revealed normal higher mental function. He had no wasting but diffused fasiculations including the tongue, nasal speech, difficulty swallowing, hypotonia, power grade $3+$ for proximal and distal muscles with hyporeflexia and superficial reflexes were normal with bilateral flexor plantar response. Examination of his sensory system, 
extrapyramidal system, and autonomic system (bedside tests) showed no abnormality. Examinations of other systems were within the normal limit

Hematologic, biochemical, toxicologic investigations, and neuroimaging were normal including thyroid and parathyroid function test, vitamin D, and serum calcium. Nerve conduction study (NCS) and electromyography (EMG) revealed signs of denervation

\section{Discussion and conclusion:}

We present a case with an MND diagnosis who remit spontaneously defined by clinical and electroneuromyography studies.

Our case presented with acute onset of progressive bulbar and limb weakness of lower motor neuron type. The symptoms were timed with clove oil intake in a high dose as a trial to control his high blood sugar. Clove oil is well known for its healing effect for inflammatory conditions, especially for dental and skin inflammation. However, clove oil cytotoxicity was examined and attributed mainly to its eugenol constituent eugenol.

Although eugenol is considered safe as a product, due to the vast range of different applications and extensive use, there has been great concern about its toxicity in recent years. The cytotoxic effects of eugenol, induction of reactive oxygen species (ROS) production, and reduced levels of glutathione (GSH) have been studied in a human submandibular cell line. It is suggested that the formation of benzyl radicals is the main cause of low GSH of eugenol is found to be related to ROS- independent mechanisms [11,12]

Another study evaluated the apoptosis induced by eugenol in human breast cancer cells. Release of the lactate dehydrogenase enzyme, percentage of cell viability and cytotoxicity, morphological changes, and quantitation of DNA fragments have been studied. The findings demonstrated that the increase of cell apoptosis and DNA fragmentation are dose-dependent [13].

Observations also showed that eugenol and safrole are able to produce a positive recombinogenic response which is related to a high CYP P450 activation capacity. The genotoxicity of eugenol is related to reactive metabolites and recombinogenic compounds of it [14].

\section{References}

1. Ludolph A, Drory V, Hardiman O, Nakano I, Ravits J, et al. (2015) A revision of the El Escorial criteria - 2015. Amyotroph Lateral Scler Frontotemporal Degener. 16(5-6): 291-292.

2. Younger DS, Rowland LP, Latov N, Hays AP, Lange DJ, et al. (1991) Lymphoma, motor neuron diseases, and amyotrophic lateral sclerosis. Ann Neurol. 29(1): 78-86.

3. Freedman DM, Curtis RE, Daugherty SE, Goedert JJ, Kuncl RW, et al. (2013) The association between cancer and amyotrophic lateral sclerosis. Cancer Causes Control. 24(1): 55-60.

4. Blecher R, Elliott MA, Yilmaz E, Dettori JR, Oskouian RJ, et al. in form of fasciculations, fibrillations, and positive sharp waves with signs of reservation in form of neurogenic motor units action potential. the patient was diagnosed with a case of anterior horn cell disease of Progressive Muscular Atrophy (PMA) subtype. After 2 weeks, the patient recovered spontaneously both clinically and electro diagnostically after having tonics only.

In our case, blood and serum toxicology screens were normal but these were for minerals. while clove oil ingredients including eugenol couldn't be examined. We proposed clove oil toxicity from the patient's scenario and timing to oil intake. In addition, the patient had no other co-morbid conditions except DM which is not known to have a similar presentation. The patient's spontaneous recovery both clinically and diagnostically made us think of the effect of the toxin. Our case is not the first one with spontaneous resolution of anterior horn cell disease. There are further cases described in the literature. Mulder and Howard [15] reported that, during the period of 20 years examining more than 2,000 patients with amyotrophic lateral sclerosis (ALS), they had seen "several" patients who were initially diagnosed with ALS but subsequently recovered.

Tucker and Layzer [16] described four patients with a clinical syndrome closely resembling ALS that recovered completely in 5-12 months after onset. In 1993, Tsai et al [17] described the latest case of a clinically resembling ALS that recovered completely in approximately 1.5 years without having any underlying systemic disease, malignancy, or intoxication.

There are no reports regarding the eugenol effect on motor neurons but it could be attributed to the release of ROS. However, further studies are required to prove the effect of eugenol or maybe other clove oil gradients on motor neurons.

Some herbal ingredients may be toxic to the nervous system and need to be aware of the possibility of toxicity in any neurodegenerative disorders especially in elderly people from regions with beliefs in herbal medicine.

(2019) Contact Sports as a Risk Factor for Amyotrophic Lateral Sclerosis: A Systematic Review. Global Spine Journal. 9(1): 104118

5. Saito T, Irie S, Ito H, Kowa H (1992) Paraproteinemia and motor neuron disease. Rinsho Shinkeigaku. 32(10): 1146-8.

6. Sutedja NA, Veldink JH, Fischer K, Kromhout H, Heederik D, et al. (2009) Exposure to chemicals and metals and risk of amyotrophic lateral sclerosis: A systematic review. Amyotrophic Lateral Sclerosis. 10(5-6): 302-309.

7. Hozumi I, Hasegawa T, Honda A, Ozawa K, Hayashi Y, et al. 
(2011) Patterns of levels of biological metals in CSF differ among neurodegenerative diseases. J Neurol Sci. 303(1-2):95-99.

8. Ibrahimagic OC, Sinanovic O, Zonic L, Hudic J (2006) Amyotrophic lateral sclerosis in younger age associated with abnormality of copper level. Med Arh. 60(2): 108-109.

9. Roberts BR, Lim NK, McAllum EJ, Donnelly PS, Hare DJ, et al. (2014) Oral treatment with $\mathrm{Cu}(\mathrm{II})(\mathrm{atsm})$ increases mutant SOD1 in vivo but protects motor neurons and improves the phenotype of a transgenic mouse model of amyotrophic lateral scle rosis. $\mathrm{J}$ Neurosci. 34(23): 8021-8031.

10. Chaieb K, Zmantar T, Ksouri R, Hajlaoui H, Mahdouani K, et al. (2007) Antioxidant properties of the essential oil of Eugenia caryophyllata and its antifungal activity against a large number of clinical Candida species. Journal Compilation Ó 2007 Blackwell Publishing Ltd. Mycoses. 50(5): 403-406.

11. Prashar A, Locke IC, Evans CS (2006) Cytotoxicity of clove ( Syzygium aromaticum ) oil and its major components to human skin cells. Cell Prolif. 39(4): 241-248.

12. Atsumi T, Fujisawa S, Satoh K, Sakagami H, Iwakura I, et al. (2000) Cytotoxicity and radicalintensity of eugenol, isoeugenol or related dimers. Anticancer Res. 20(4): 2519-2524.

13. Vidhya N, Devaraj SN (2011) Induction of apoptosis by eugenol in human breast cancer cells. Indian J Exp Biol. 49(11): 871-878.

14. Munerato MC, Sinigaglia M, Reguly ML, de Andrade HHR (2005) Genotoxic effects of eugenol, isoeugenol and safrole in the wing spot test of Drosophila melanogaster. Mutat Res. 582(1-2): $87-94$

15. Mulder DW, Howard FM, Jr. (1976) Patient resistance and prognosis in amyotrophic lateral sclerosis. Mayo Clin Proc. 51(9): 537-541.

16. Tucker T, Layzer RB, Miller RG, Chad D (1991) Subacute, reversible motor neuron disease. Neurology. 41(10): 1541-4.

17. Tsai CP, Ho HH, Yen DJ, Wang V, Lin KP, et al. (1993) Reversible motor neuron disease. Eur Neurol. 33(5): 387-9. 